\title{
THE
}

\section{Stochastic frontier analysis of total factor productivity in the offshore oil and gas industry}

\author{
Shunsuke Managi \\ James J. Opaluch \\ University of Rhode Island, jimopaluch@uri.edu \\ Di Jin
}

Thomas A. Grigalunas

University of Rhode Island, tomgrig@uri.edu

Follow this and additional works at: https://digitalcommons.uri.edu/enre_facpubs

This is a pre-publication author manuscript of the final, published article.

Creative Commons License

(c) (i) $\Theta$

This work is licensed under a Creative Commons Attribution-Noncommercial-No Derivative Works 4.0 License.

\author{
Citation/Publisher Attribution \\ Managi, S., Opaluch, J. J., Jin, D., \& Grigalunas, T. A. (2005). Stochastic frontier analysis of total factor \\ productivity in the offshore oil and gas industry. Ecological Economics, 60(1), 204-215. doi: 10.1016/ \\ j.ecolecon.2005.11.028 \\ Available at: https://doi.org/10.1016/j.ecolecon.2005.11.028
}

This Article is brought to you for free and open access by the Environmental and Natural Resource Economics at DigitalCommons@URI. It has been accepted for inclusion in Environmental and Natural Resource Economics Faculty Publications by an authorized administrator of DigitalCommons@URI. For more information, please contact digitalcommons-group@uri.edu. 


\title{
Stochastic Frontier Analysis of Total Factor Productivity in the Offshore Oil and Gas Industry
}

\author{
Shunsuke Managi ${ }^{a *}$, James J. Opaluch ${ }^{\mathrm{b}}$, Di Jin ${ }^{\mathrm{c}}$ and Thomas A. Grigalunas ${ }^{\mathrm{b}}$ \\ ${ }^{a}$ Faculty of Business Administration \\ International Graduate School of Social Sciences \\ Yokohama National University \\ 79-4, Tokiwadai, Hodogaya-ku \\ Yokohama 240-8501 Japan \\ Phone: +81-45-339-3720 \\ Fax: +81-45-339-3707 \\ managi@ynu.ac.jp \\ * Corresponding author \\ ${ }^{\mathrm{b}}$ Department of Environmental and Natural Resource Economics \\ University of Rhode Island \\ Kingston, Rhode Island 02881 USA \\ ${ }^{\mathrm{c}}$ Marine Policy Center \\ Woods Hole Oceanographic Institution \\ Woods Hole, Massachusetts 02543 USA
}

November 2005

The authors thank four anonymous referees for helpful comments. This research was funded by the United States Environmental Protection Agency STAR grant program (Grant Number Grant Number R826610-01) and the Rhode Island Agricultural Experiment Station (AES Number 5034). The results and conclusions of this paper do not necessary represent the views of the funding agencies. 


\title{
Stochastic Frontier Analysis of Total Factor Productivity in the Offshore Oil and Gas Industry
}

\begin{abstract}
We examine the impact of technological change on oil and gas exploration, development and production in the Gulf of Mexico over the past five decades. We analyze the effect of technological change on the production frontier using a unique field-level data set covering 1947 through 1998. We then develop estimates of the growth in total factor productivity (TFP) in the industry at the regional level from 1976 to 1995 . To address the unique features of this marine resource industry, we include in our models some key geological variables such as water depth and field size. In addition, the results reveal that environmental regulation had a significantly negative impact on offshore production, although such impact has been diminishing over time.
\end{abstract}

JEL codes: D24, Q32, L71

Key words: technological change, productivity, stochastic frontier analysis, environmental regulation, and offshore oil and gas industry 


\section{Introduction}

The offshore oil and gas industry has played a significant role in energy supply in the United States. Since 1947 in the Gulf of Mexico, as one of the first large-scale offshore production areas in the world, the share of offshore production in the total domestic production has been increasing. In 2001, Federal offshore oil and gas production accounted for 26.3 and 24.3 percent of total U.S. production, respectively (U.S. Department of Interior 2001). Oil and gas production in the Gulf, our study region, accounted for 88 and 99 percent of the total U.S. offshore production in 1997, respectively (U.S. Department of Interior 1997). Contrary to earlier predictions of declining production due to resource depletion (Walls 1994), the output from the Gulf of Mexico has increased in recent years.

Offshore oil and gas operations take place in a much more difficult natural environment than onshore operations. Generally, the long run path of offshore oil and gas production is the net result of two opposing forces: forces that reduce costs by technological change, and forces that increase costs by cumulative depletion and the associated decline in resource accessibility such as exploitation moving to fields that are more remote, deeper and smaller. In the past five decades, offshore operations in the Gulf of Mexico expanded first along the coast in shallow waters, and then extended into deep waters. The continued development and production in the region has depended heavily on technological innovation.

The purpose of this study is to examine the role technological change in conjunction with environmental regulation has played in the offshore industry. We first analyze the effect of technological change on the production frontier using a unique field-level data set, and we then develop estimate of the growth in total factor productivity (TFP) in the industry at the regional level. 
Introductions to offshore technologies can be found in many studies (e.g., Massachusetts Institute of Technology 1973; Giuliano 1981; Farrow et al 1990; Bohi 1997). Several recent technological innovations have had significant impact on the offshore industry. Three-dimensional (3D) seismic technology became available in the mid-1980s and has been widely used since 1992 (U.S. Department of the Interior 1996). The higher-quality images from 3D seismology greatly improved the ability to locate new hydrocarbon deposits, to determine the characteristics of reservoirs for optimal development, and to help determine the best approach for producing from a reservoir. The new technology has substantially increased the success rate of both exploratory and development wells, which has led to reductions in the number of wells drilled for a deposit as well as in exploration and development cost.

Horizontal drilling technology has developed rapidly since the late 1980s. The technology involves a steerable downhole motor assembly and a "measurement-while-drilling" package. With horizontal drilling technology, drillers are capable of guiding a drillstring that can deviate at all angles from vertical. Thus, the wellbore intersects the reservoir from the side rather than from above (U.S. Department of Energy 1993). Horizontal drilling has been widely used offshore to reach deposits far away from fixed platforms, by that increasing access to distant reserves and lowering the cost of production.

Deep-water technology encompasses two production systems: tension leg platforms (TLPs) and subsea completions. TLPs float above the offshore field and are anchored to the sea floor by hollow steel tubes. TLPs have been used in several deep-water fields in the Gulf of Mexico. Although deep-water technologies are mostly used for offshore development and production, they provide a driving force for explorations in deep waters. 
There has been a growing literature on technological change and petroleum exploration and development. In a study of natural gas exploration and discovery in the U.S. lower 48 states, Cleveland and Kaufmann (1997) found that depletion effects had outweighed technological improvements from 1943 to 1991. By contrast, Fagan (1997) found that technological change had offset resource depletion in her analysis of onshore and offshore oil discovery costs from 27 large U.S. oil producers over the 1977-1994 periods. Cuddington and Moss (2001) have reached the same conclusion from their analysis of the cost of finding additional petroleum reserves (cost of exploration and development) from 1967 to 1990.

Jin, Kite-Powell and Schumacher (1998) developed a framework for the estimation of total factor productivity (TFP) in the offshore oil and gas industry. Their model extends conventional TFP measurement by accounting for the effects of increasing water depth and declining field size. They applied the model using regional data in Gulf of Mexico and developed preliminary estimates for TFP change from 1976 to 1995 . The results suggest that productivity change in the offshore industry has been remarkable.

In a separate study using our field-level data on production and Data Envelopment Analysis (DEA), we found that the effect of technological progress dominated that of resource depletion in production from fields (Managi et al, 2004a). Statistical relevance of results, however, is not provided. We obtain similar conclusion using the discovery of new fields that the effect of technological progress dominated that of resource depletion in discovery process from fields (Managi et al, 2005a). Inefficiency in field level activity, however, is not considered. In this study, we consider the inefficiency in field level production and analyze the impact of technology and the other relevant variables statistically. 
We also consider the effect of environmental regulations on field-level production frontier as well as on regional-level productivity measurement (Barbera and McConnell 1990). Several studies have examined how the oil and gas industry responds to changes in environmental regulations in the literature. Kunce et al. (2004), for example, examines how the oil and gas industry responds to changes in environmental and land use regulations pertaining to drilling. A simulation model for Wyoming shows that drilling and future production are sensitive to changes in costs associated with environmental and land use regulations.

Since the 1970s, the offshore oil and gas industry has been subject to multiple environmental regulations. Under the Clean Water Act of 1972, the Environmental Protection Agency (EPA) first limited the disposal of free oil in drilling muds and issued effluent discharge standards based on existing technologies in 1975. Standards for toxic and nonconventional pollutants in effluent discharges and drilling muds were added in 1986, along with limits on oil and grease in produced water. In 1993, discharge standards were revised and expanded to cover drilling fluids and cuttings; produced water; deck drainage; treatment, completion and workover fluids; and domestic and sanitary wastes for most of the OCS (outer continental shelf). These standards were extended to the Western Gulf of Mexico portion of the OCS in 1998-99. ${ }^{1}$ In addition, under the Clean Air Act, the national ambient air quality standards first became applicable to most of the OCS in 1990. The standards became applicable to the Western Gulf of Mexico in 1993.

The paper is organized as follows. Section 2 presents the methods of our stochastic frontier analysis and TFP assessment. Empirical data used in the study are described in section 3. We discuss the results in section 4. Conclusions are summarized in section 5.

1 Typically, EPA regulations have taken effect several years later in the Western Gulf of Mexico, where most US offshore oil and gas installations are concentrated, than in other areas of the OCS. 


\section{Methods}

The offshore oil and gas industry is a nonrenewable resource industry and its production is affected by resource stock size (e.g., oil and gas reserves) and quality (e.g., field size and reservoir type). Unlike onshore production, the offshore industry must develop new offshore production technologies to accommodate increasing water depth as shallow water resources are depleted. In fact, offshore oil and gas production at any given time is conditioned on certain marine geological and technical factors. For example, without the recent deep-water technologies, production from deep-water fields would not have occurred. Finally, the industry must comply with relevant environmental regulations. Thus, for the offshore oil and gas industry, a general production function may be specified as (see Appendix for derivation of production in exploration-extraction model):

$$
\left.{ }_{\mathrm{t}}=F \mathrm{X}_{\mathrm{t}}, D, S, R_{t}, E_{t}, t\right)
$$

where $\mathbf{y}_{\mathbf{t}}$ is the vector of outputs (i.e., oil and gas) at time $\mathbf{t}, \mathbf{x}_{\mathbf{t}}$ is the vector of factor inputs (e.g., drillings and platforms), $D$ is the water depth, $S$ is the field size, $\mathrm{R}_{\mathrm{t}}$ is the depletion through time $\mathrm{t}, E$ is the stringency of environmental regulations ${ }^{2}$, and $t$ is time. The above specification extends the classical production function (Solow, 1957) by explicitly including attribute variables $D, S, R$ and $E$. The extension is essential for the study of the offshore oil and gas industry.

Generally, equation (1) is valid for data at the disaggregate field-level and the aggregate regional level. We will first examine the field-level production using a stochastic frontier model ${ }^{3}$ and then estimate changes in TFP at the regional level using an aggregate model ${ }^{4}$.

See Stijn et al (2002) for the literature review of stochastic frontier analysis in pollution control.

Although stochastic frontier models have been used for measuring technological change, the results are usually sensitive to parameterization (see Hjalmarsson, Kumbhakar and Heshmati 1996). In the study, we will not estimate technological change using the stochastic frontier model. 
The stochastic frontier production function was initially developed by Aigner, Lovell and Schmidt (1977) and Meeusen and van den Broeck (1977). Battese and Coelli (1992) present a stochastic frontier model for unbalanced panel data with fixed effects. The effects are assumed to be distributed as truncated normal random variables, and also permitted to vary systematically with time. Löthgren (1997) extend the stochastic frontier analysis by introducing a stochastic ray frontier model to accommodate the case of multiple outputs.

In our study, we have two outputs, oil and gas. Following Löthgren, we obtain a scalar valued representation of the multiple output technology by using a polar coordinate representation of the output vector $(y)$ as follows:

$$
y=\iota \cdot m(\theta)
$$

where $\iota$ is the Eulidean norm (length) of the output vector $y, m$ is a function representing output mix, and $\theta$ is the polar coordinate angle. ${ }^{5}$ Figure 1 illustrates the polar coordinate representation in the two output case.

The stochastic ray frontier production function model can be specified as:

$$
\iota=f(x, \theta) \exp (v-u)
$$

where $v$ and $u$ form the composite error term in a standard stochastic frontier model, where $u$ is a truncated random variable capturing inefficiency in production and $\mathrm{v}$ is a normal error term representing measurement error. Our specification of (3) is:

$$
\ln \iota_{i t}=\alpha+\beta \ln x_{i t}+\gamma \theta_{i t}+v_{i t}-u_{i t}
$$

where $i$ is the field index and $t(=1, \ldots, \mathrm{T})$ is time (i.e., year). $\iota_{i t}$ is the norm of field $i$ at time $t, \mathrm{x}_{i t}$ is a vector of the inputs $(x)$ and $\theta_{i t}$ is an output angles. $v_{i t}$ is the random noise term,

4 Some cost data are available only in aggregated level and therefore we utilize the cost elasticity information to estimate TFP.

5 For detailed description of the method and calculation of $\theta$, see Löthgren (1997). 
independently and identically distributed as $N\left(0, \sigma_{v}^{2}\right) . u_{i t}$ accounts for technological inefficiency in production, defined as $u_{i} \exp (-\eta(t-T))$ with $u_{i}$ being a non-negative random variable truncated at 0 , and independently and identically distributed as $N\left(\mu, \sigma_{u}^{2}\right) . \alpha, \beta, \gamma$, and $\eta$ are the parameters to be estimated.

In our field-level analysis, we use cumulative values for factor inputs (elements of $x$ ) and outputs $(y)$, because for the above technology definition, it is more appropriate to express the production relationship on cumulative terms for a nonrenewable industry. For example, for a field, the production at $t$ is determined by cumulative inputs (e.g., drilling) up to $t-1$.

We have two outputs: cumulative oil production in barrels and cumulative gas production in thousand cubic feet. We examine a number of input/explanatory variables (i.e., elements of vector $x$ ). The effects of technological change are captured by three technical variables. Tech is the cumulative weighted technological innovation index as described below ${ }^{6}$. The variable horizontal $^{\text {exp }}$ represents the extent to which horizontal/directional drilling is used in exploratory wells, and is defined as the ratio of cumulative drilling distance to the corresponding vertical depth. A higher ratio reflects greater degree of horizontal/directional drilling in the field. Similarly, horizontal ${ }^{\text {dev }}$ represents the level of horizontal drilling in development wells. The expected signs of these three technical variables are positive, since technological change leads to increases in output.

In most empirical analyses, the effect of technological level is usually examined by including a time-trend or dummy variables in regression models ${ }^{7}$. Moss (1993) and Cuddington and Moss (2001) construct a technology index based on counting specific technological

$6 \quad$ Alternative indexes of technologies are technological change index estimated in Data Envelopment Analysis or Stochastic Frontier Analysis. These are, however, measures of shifts in a production frontier. If we employ either of them, it is less relevant structural model since we measure the production frontier using the one measure of the frontiers. See Managi (2002) for the results using frontier techniques as a proxy for Tech. 
diffusions in the exploration-development sector of the oil and gas industry (i.e., the number of technological innovations adopted by the industry) from 1947 to 1990. For their index, Cuddington and Moss treat all innovations the same and do not differentiate technological innovations in terms of their impacts on productivity improvements in the industry. In this study, we construct an alternative technology index as follows. First, we extend the Moss (1993) index from 1991 to 1998. Specifically, we collect information from Oil and Gas Journal and Hart's Petroleum Engineer International (formerly Petroleum Engineer International) to construct our technology index following the methodology described by Moss (1993) ${ }^{8}$. Examples of major innovations in the 1990s include 3D seismic data acquisition, and horizontal drilling ${ }^{9}$. We then use data from the National Petroleum Council (NPC 1995) to weight each innovation ${ }^{10}$. The NPC data contain survey results of firms' rankings of short and long-term impacts of specific technologies on the industry. Our technological innovation index covers the explorationdevelopment-production stage and is constructed as

$$
\operatorname{Tech}_{t}=\sum_{t=t_{0}}^{t} \sum_{i} w_{i t} \times N_{i t} .
$$

where $\operatorname{Tech}_{t}$ is the cumulative weighted technological innovation index at time $t ; w_{i t}$ is the weight for innovations in technology category $i$ at time $t ; N_{i t}$ is the number of technological innovations in technology category $i$ at time $t$. As noted, $N$ covers all exploration-development-production stage innovations.

$7 \quad$ See Fagan (1997) for example.

8 This rule consists of four steps: (i) gathering information on relevant technologies; (ii) sorting collected materials by category of technology; (iii) compiling a chronology of technological developments for each category of technology; and (iv) dating the technological innovations. See Managi et al. (2006) for the validity of this index.

9 See Managi (2002) for a precise description of post-1990 innovations and Moss (1993) for pre-1990 innovations.

10 For example, innovation in horizontal drilling is considered more significant than innovation in depth mapping. Thus, horizontal drilling gets higher weight than depth mapping. The weights are normalized to sum to one. For specific calculation of weights, see Managi (2002). 
We consider five conventional factor input variables: the cumulative number of exploratory and development wells up to $t-1$ (well); the cumulative average drilling distance (in feet) per exploratory well $\left(\right.$ drill $\left.^{\text {exp }}\right)$, calculated as the cumulative drilling distance divided by the cumulative number of wells; the cumulative average drilling distance (in feet) per development well (drill $\left.{ }^{d e v}\right)$; the number of platforms (platform); and platform size, measured as average number of slots per platform for the field (platform size). Positive signs are expected for these variables capturing drilling and production inputs.

To account for specific field characteristics, we include several geophysical variables: the remaining reserves in the field at $t-1$ in million BOE (barrel of oil equivalent), the field size in million BOE, water depth of a field in feet, the average porosity of reservoirs in the field, measured in percent terms and the volume of untreated produced water in barrels. ${ }^{11}$ The expected signs for reserves, field size, and porosity are positive, since larger reserve size is generally associated with higher production, and higher porosity implies greater flow rate lower production cost. The expected sign for water depth is negative, as exploration, development and production of fields tent to be more costly in deeper waters. The expected sign for produced water is negative, as additional inputs are needed to reduce water production for a field at a particular point in time. Finally, production is adversely affected by the stringency of environmental regulations governing offshore oil and gas operations. We measure environmental stringency as the estimated environmental compliance cost in dollars per unit of oil and gas production.

Although the production function (1) provides a nice description of how outputs are affected by conventional inputs (e.g., capital and labor) and other factors, it is not convenient for the measurement of total factor productivity (TFP). We examine instead the cost function to estimate 
the change in TFP in the offshore industry at the regional level following Denny, Fuss and Waverman (1981) and Jin et al. (1998). Assuming that firms in the industry minimize cost, duality theory suggests that for any well-behaved production function (1), there exists a cost function that provides an equivalent description of the technology (e.g., Fuss and McFadden, 1978). We write the conditional cost function as:

$$
C=g\left(w_{1}, \ldots ., w_{n}, Y_{o}, Y_{g}, D, S, E, Q, t\right)
$$

where $w_{i}(i=1, \ldots, n)$ is the price of factor input $i, Y_{o}$ and $Y_{g}$ are output quantities of oil and gas, $D$ is the water depth, $S$ is the field size, $E$ is the effect of environmental regulation following Gollop and Roberts (1983), $Q$ is pollution discharge (e.g., produced water and oil spills), and $t$ is time. The term "conditional" is used to indicate that the cost is conditioned on a fixed set of attributes (e.g., field size).

Generally, for a given technology, production cost is related inversely to stock size (Pindyck 1978) and positively to cumulative discovery (Livernois and Uhler 1987). The average field size in a region decreases as cumulative discovery rises and it generally implies a decline in the stock size. In this study, we use the average field size $(S)$ in the region to represent the stock factor and $\partial C / \partial S<0$

The offshore industry must develop new production technologies to accommodate increasing water depth as shallow water resources are depleted. Offshore oil and gas production at any given time is conditioned on certain marine geophysical and technical factors. We use average water depth $(D)$ of all active fields at $t$ in the region to represent the physical and technical factors of the industry. For a given technology, cost increases with water depth and therefore $\partial C / \partial D>0$.

11 We follow the usual convention in environmental economics of treating pollution emissions as an input to production (e.g., Baumol and Oates, 1988; Cropper and Oates, 1992). Thus, a reduction (increase) in untreated produced water, with all other inputs and outputs held fixed, represents an increase (decrease) in productivity. 
Offshore oil and gas exploration and production are subject to environmental regulations (Jin and Grigalunas 1993a, 1993b; American Petroleum Institute 1995). As noted, these regulations have been designed to control the discharge of drilling wastes and produced water. We use variable $E$ to denote regulatory intensity (Gollop and Roberts 1983) and, all else equal, the cost increases with more stringent regulation, i.e., $\partial C / \partial E>0$.

Productivity measures should account for external effects (Barbera and McConnell 1990). For example, a reduction in pollution from offshore oil could result in an increase in productivity of commercial fisheries. Thus, with all other inputs and outputs held fixed, a reduction (increase) in water pollution represents an increase (decrease) in productivity. We follow the usual convention in environmental economics of treating pollution emissions $(Q)$ as an input to production (e.g., Baumol and Oates, 1988; Cropper and Oates, 1992). Generally, $\partial C / \partial Q>0$.

Following Jin et al. (1998), we define TFP as the shift in the cost function $(g)$ in the study. Differentiating Equation (6) with respect to time $(t)$ we obtain

$$
\frac{\partial C}{\partial t}=\sum_{i} \frac{\partial g}{\partial w_{i}} \frac{d w_{i}}{d t}+\sum_{j} \frac{\partial g}{\partial Y_{j}} \frac{d Y_{j}}{d t}+\frac{\partial g}{\partial D} \frac{d D}{d t}+\frac{\partial g}{\partial S} \frac{d S}{d t}+\frac{\partial g}{\partial E} \frac{d E}{d t}+\frac{\partial g}{\partial Q} \frac{d Q}{d t}+\frac{\partial g}{\partial t}
$$

where $\mathrm{j}=(\mathrm{o}, \mathrm{g})$. Dividing through by $\mathrm{C}$ and applying Shephard's lemma $\left(\partial \mathrm{g} / \partial \mathrm{w}_{\mathrm{i}}=\mathrm{X}_{\mathrm{i}}\right)$ yields:

$$
\frac{\dot{C}}{C}=\sum_{i} \frac{w_{i} X_{i}}{C} \frac{\dot{w}_{i}}{w_{i}}+\sum_{j} \varepsilon_{C Y_{j}} \frac{\dot{Y}_{j}}{Y_{j}}+\varepsilon_{C D} \frac{\dot{D}}{D}+\varepsilon_{C S} \frac{\dot{S}}{S}+\varepsilon_{C E} \frac{\dot{E}}{E}-\varepsilon_{C Q} \frac{\dot{Q}}{Q}+\frac{1}{C} \frac{\partial g}{\partial t}
$$

where $\varepsilon$ is the cost $(C)$ elasticity with respect to relevant explanatory variables. In deriving Equation (8), we treat water depth $(D)$, field size $(S)$, and environmental regulation $(E)$ as exogenous. However, pollution discharge $(Q)$ is considered endogenous like other factor inputs. ${ }^{12}$ Thus, we have a negative sign for the last term in Equation (8).

Since $C=\sum_{i} w_{i} X_{i}$, we have 


$$
\sum_{i} \frac{w_{i} X_{i}}{C} \frac{\dot{w_{i}}}{w_{i}}-\frac{\dot{C}}{C}=-\sum_{i} \frac{w_{i} X_{i}}{C} \frac{\dot{X_{i}}}{X_{i}}
$$

In the study, we define TFP as the shift in the cost function (g). Substituting Equation (9) into Equation (8) and rearranging, we have an expression for the proportional rate of shift in the cost function $(1 / \mathrm{C})(\partial \mathrm{g} / \partial \mathrm{t})$.

$$
-\frac{1}{C} \frac{\partial g}{\partial t}=\sum_{j} \varepsilon_{C Y_{j}} \frac{\dot{Y}_{j}}{Y_{j}}-\sum_{i} \frac{w_{i} X_{i}}{C} \frac{\dot{X}_{i}}{X_{i}}+\varepsilon_{C D} \frac{\dot{D}}{D}+\varepsilon_{C S} \frac{\dot{S}}{S}+\varepsilon_{C E} \frac{\dot{E}}{E}-\varepsilon_{C Q} \frac{\dot{Q}}{Q}
$$

Assuming that the firms in the offshore industry engage in marginal cost pricing $\left(\partial \mathrm{C} / \partial \mathrm{Y}_{\mathrm{j}}=\right.$ $\mathrm{p}_{\mathrm{j}}$ ) and denoting $R=\sum_{j} p_{i} Y_{j}$, Equation (10) becomes

$$
-\frac{1}{C} \frac{\partial g}{\partial t}=\sum_{j} \varepsilon_{C Y_{j}} \sum_{j} \frac{p_{j} Y_{j}}{R} \frac{\dot{Y}_{j}}{Y_{j}}-\sum_{i} \frac{w_{i} X_{i}}{C} \frac{\dot{X}_{i}}{X_{i}}+\varepsilon_{C D} \frac{\dot{D}}{D}+\varepsilon_{C S} \frac{\dot{S}}{S}+\varepsilon_{C E} \frac{\dot{E}}{E}-\varepsilon_{C Q} \frac{\dot{Q}}{Q}
$$

The conventional definition of proportional change in TFP (Jorgenson and Griliches 1967) is

$$
\frac{\dot{A}}{A}=\sum_{j} \frac{p_{j} Y_{j}}{R} \frac{\dot{Y}_{j}}{Y_{j}}-\sum_{i} \frac{w_{i} X_{i}}{C} \frac{\dot{X}_{i}}{X_{i}}
$$

where $\frac{\dot{A}}{A}$ is the conventional definition of proportional change in TFP (Jorgenson and Griliches 1967). Thus, if the cost function exhibits constant returns to scale $\left(\sum_{j} \varepsilon_{C Y_{j}}=1\right)$ with respect to factor inputs, Equation (11) can be rewritten as

$$
-\frac{1}{C} \frac{\partial g}{\partial t}=\frac{\dot{A}}{A}+\varepsilon_{C D} \frac{\dot{D}}{D}+\varepsilon_{C S} \frac{\dot{S}}{S}+\varepsilon_{C E} \frac{\dot{E}}{E}-\varepsilon_{C Q} \frac{\dot{Q}}{Q} .
$$

We know that the average water depth and the stringency of environmental regulations have been increasing while average field size has been decreasing over time. Since $\varepsilon_{C D}>0, \varepsilon_{C S}<0$, 
$\varepsilon_{C E}>0$, and $\varepsilon_{C Q}>0$, the second, third and fourth terms on the right hand side of (13) are positive. If environmental discharge decreases over time, the last term is also positive. Equation (13) suggests that in the case of offshore oil and gas, the conventional measure of TFP change $\left(\frac{\dot{A}}{A}\right)$ will underestimate the level of technological change by excluding the effects of water depth, field size and environmental regulations.

For empirical estimation, the Tornqvist approximation for $\frac{\dot{A}}{A}$ is:

$\ln \left[\frac{A(t)}{A(t-1)}\right]=\frac{1}{2} \sum_{j}\left[s_{Y_{j}}(t)+s_{Y_{j}}(t-1)\right] \ln \left[\frac{Y_{j}(t)}{Y_{j}(t-1)}\right]-\frac{1}{2} \sum_{i}\left[s_{X_{i}}(t)+s_{X_{i}}(t-1)\right] \ln \left[\frac{X_{i}(t)}{X_{i}(t-1)}\right]$

with

$$
s_{Y_{j}}=\frac{p_{j} Y_{j}}{\sum_{j} p_{j} Y_{j}}, \quad s_{X_{i}}=\frac{w_{i} X_{i}}{\sum_{i} w_{i} X_{i}}
$$

where $t$ is discrete time (year), $X_{i}$ is the quantity of factor input $i$ (i.e., wells and platforms), $Y_{j}(j=$ oil or gas) is the quantity of output $j, p_{j}$ is the output price of $Y_{j}$, and $s_{X i}$ and $s_{Y j}$ are cost and revenue shares. A general discussion of the standard method for growth accounting in its continuous time (Divisia index) form and in discrete time (Tornqvist) approximations can be found in Jorgenson and Griliches (1967), Christensen and Jorgenson (1995), and Hulten (1986). A more detailed discussion of Tornqvist and other index numbers can be found in Diewert (1976, 1978 and 1992) and Fisher (1922).

We develop estimates of TFP change at the regional level using Equations (13) and (14). The approach has two major advantages. First, it captures the full effect in TFP change from offshore exploration, development and production in the entire region over a long period of time. 
Also, it involves only relatively simple computation. ${ }^{13}$ However, the approach has it limitations. Most importantly, we are unable to develop precise empirical TFP estimates using Equation (13), since the elasticities $(\varepsilon)$ cannot be accurately measured due to lack of relevant data. We will use sensitivity analysis to partially compensate this problem.

\section{Data}

Our study region is the Gulf of Mexico. Offshore exploration-development-production data used in the analysis are obtained from the U.S. Department of the Interior, Minerals Management Service (MMS), Gulf of Mexico OCS Regional Office. Specifically, we develop our project database using five MMS data files:

(1) Production data, including monthly oil, gas, and produced water outputs from every well in the Gulf of Mexico over the period from 1947 to 1998. The data include a total of 5,064,843 monthly observations for 28,946 production wells.

(2) Borehole data describing drilling activity of each of 37,075 wells drilled from 1947 to 1998.

(3) Platform data with information on each of 5,997 platforms, including substructures, from 1947 to 1998.

(4) Field reserve data including oil and gas reserve sizes and discovery year of each of 957 fields from 1947 to 1997.

(5) Reservoir-level porosity information from 1974-2000. This data includes a total of 15,939 porosity measurements from 390 fields (see Appendix B).

Thus, the project database is comprised of well-level data for oil output, gas output, produced water output, and the quantity of fluid injected, and field-level data for the number of exploration wells drilled, total drilling distance of exploration wells, total vertical distance of

13 By contrast, other methods such as DEA require much more intensive computation. 
exploration wells, number of development wells drilled, total drilling distance of development wells, total vertical distance of development wells, number of platforms, total number of slots, total number of slots drilled, water depth, oil reserves, gas reserves, original proved oil and gas combined reserves in BOE, discovery year, and porosity. ${ }^{14}$

Although we have well-level production data, the well level is not a good unit for measuring technological efficiency due to spillover effects across wells within a given field. Rather, the field level is a more appropriate unit for measuring technological efficiency. For this reason the relevant variables were extracted from these MMS data files and merged by year and field. On average there are 370 fields operating in any particular year, and a total of 18,117 observations from 1947 to 1998.

In addition to our field-level exploration-production data set, we developed separate data set for environmental variables $(E$ and $Q)$. The environmental emission data set includes data of 33 different types of water pollutants in four categories from $\mathrm{EPA}^{15}$ as well as data of oil spills from the Coast Guard. To measure the level of environmental regulatory stringency over time, we use estimates of environmental compliance costs associated with preventing water pollution and oil spills. The compliance costs are based on ex-ante estimates, since we do not have the ex post cost studies. ${ }^{16}$ The compliance cost estimates are compiled from relevant regulatory

14 Detailed description of these data files can be found at http://www.gomr.mms.gov.

15 The four categories are conventional pollutants, non-conventional organic pollutants, non-conventional metal pollutants, and radionuclides. Conventional pollutants include oil and grease, and TSS. Non-conventional organic pollutants include Benzene, Benzo(a)pyrene, Chlorobenzene, Di-n-butylphthalate, Ethylbenzene, nAlkanes, Naphthalene, P-Chloro-M-cresol, Phenol, Steranes, Toluene, Triterpanes, Total xylenes, 2-Butanone, and 2,4-Dimethylphenol. Non-conventional metal pollutants include Alminum, Arsenic, Barium, Boron, Cadmium, Copper, Iron, Lead, Manganese, Mercury, Nickel, Silver, Titanium and Zinc. Radionuclides include Radium 226 and Radium 228.

16 Harrington, Morgenstern and Nelson (2000) examined ex ante versus ex post cost estimates of environmental regulations, and concluded that for EPA and OSHA rules, ex ante estimates of unit pollution reduction cost were often accurate. 
announcements published in various issues of the Federal Register and from relevant EPA documents (e.g., EPA 1985, 1993).

To construct the Tornqvist input indexes (see Equation (14)), we compile costs associated with drilling and platforms $\left(w_{i}\right)$. Offshore drilling cost data from 1955 to 1996 were collected from various issues of the Joint Association Survey on Drilling Costs (JAS) published by the American Petroleum Institute. The JAS data were grouped into nine depth intervals in each of the offshore areas in the Gulf of Mexico (e.g., offshore Louisiana and offshore Texas). Our drilling data set has a total of 1,943 observations. We used the Engineering News Record (ENR, 2000) Construction Cost Index to covert costs in different years into 2000 dollars. The operating costs for platforms in the Gulf are from the U.S. Department of Energy's Costs and Indices for Domestic Oil and Gas Field Equipment and Production Operations (various issues from 1977 to 1996).

To improve precision, the regional-level input index is based on disaggregate data. For drilling activities, we first calculate the regional total number of wells by seven different drilling depth intervals, and then use the corresponding average depth in each interval group to calculate the drilling cost per well for each group using a cost function estimated using the above drilling cost data. For platforms, we process the data in 12 groups by platform size (i.e., slots) and water depth. The water depth $(D)$ and field size $(S)$ index are calculated as the weighted average water depth and field size across all producing fields for each year, and the weight for a field is the revenue share of that field.

\section{Results}


For the field-level analysis, we estimate our stochastic frontier model with three separate specifications. The first specification is for the entire data set from 1947 to 1998. Since data for stringency of environmental regulations are not available before 1968, we assess the effect of environmental regulations on offshore operation in the second specification using a separate data set including the stringency variable from 1968 to 1998, and we compare the model results with versus without the environmental variables by applying the initial specification to the data for 1968-1998. All the specifications are estimated using the Frontier Version 4.1 software (Coelli, 1994).

The results of the three specifications are summarized in Table 1. Generally, the estimated coefficients for all variables have the expected sign and reasonable magnitudes. In addition, the results are consistent across the three specifications, suggesting that our model is robust with respect to the inclusion of the environmental variable as well as variation in the length of time series.

Of the three technological variables, the technological change index (Tech) is highly significant in all three specifications, indicating that technological change has had a significant positive impact on the field-level production frontier. The coefficients for horizontal ${ }^{\text {exp }}$ are significant in Specifications 1 and 3, and the coefficients for horizontal ${ }^{d e v}$ are significant in Specifications 2 and 3. The results suggest that horizontal drilling technology has also caused a positive shift in the production frontier.

Coefficients of all five factor input variables have the expected positive sign and are significant. The results provide a numerical description of the relationship between the production frontier and input efforts, including the number of wells (well), drilling depth (drill exp $^{\text {en }}$ and $d r i l l^{d e v}$ ), the number of platforms (platform), and platform size. 
The field-level production frontier is affected by geological factors. As shown in the middle part of Table 1, most these variables are significant and only porosity in Specification 2 is not. The magnitudes of these coefficients reveal that the output quantity is mostly determined by two variables: field size and water depth. While it is obvious that larger fields produce more, it is somewhat surprising to see the magnitude of the negative impact of water depth on the production frontier. The challenge posed by water depth is indeed substantial. Generally, we expect potential of larger production is available in deep water areas. Our results show that, on average, it is not true in our study periods. This might be because industry focused on production from large filed in deep water and little attention is paid to small and average field size fields. We model produced water, a byproduct of petroleum production, on the input side. Although the volume of produced water from a field is influenced by the geological type of its reservoirs and the age of the field, our results suggest that, on average, the quantities of produced water and petroleum output are positively related.

The offshore oil and gas industry has been subject to not only challenging marine conditions but also increasing environmental regulations (see Managi et al., 2005b). To estimate associated production frontier shift, we include a measure of the stringency of environmental regulations in Specification 2 (see Table 1). The significantly negative coefficient implies that environmental regulation has indeed had a measurable impact on productivity of the offshore oil and gas industry.

We include three time interaction terms with reserves (i.e., remaining stock in a field), water depth, and environmental stringency in our model, respectively, to examine how these factors change over time $(t)$. The corresponding coefficients are all significant. The time interaction term is negative for reserves, suggesting that the positive effect of remaining resource 
stock on field-level production has been declining over time, which suggest that new technologies allow one to more efficiently exploit small fields. The time interaction terms are positive for water depth and environmental stringency. The former shows that the negative impacts of water depth and environmental regulations on the production frontier have been diminishing (becoming less negative) over time due to technological change, including less “structural" components of technological change, such as learning by doing.

The positive sign of the parameter capturing the time varying effect $(\eta)$ indicates that efficiency at the field level has increased over time, which is likely due to the learning by doing in the Gulf of Mexico (Managi et al., 2004a). Finally, the estimated polar angle $\theta$ is positive and significant. The result suggests that when the frontier output mix is changed by substituting gas production for oil production, the increase in gas production is greater than the corresponding decrease in oil production, as measured in BOE.

In summary, the results of our field level analysis indicate that the effect of technological change on the offshore oil and gas industry was substantial over the study period from 1947 to 1995. Similarly, environmental regulation also had a significant impact on offshore production. Next, we attempt to measure the magnitude of the technological change in the offshore industry.

As noted in Equation (14), the computation of the Tornqvist indexes involves the costs $\left(w_{i}\right)$ of relevant factor inputs $\left(X_{i}\right)$. We have relatively complete cost data for drilling and platforms from 1976 to 1995 . Thus, our TFP assessment is carried out for this period. Also, we include two factor input variables: the total number of exploratory and development wells, and the number of platforms. These two variables capture the bulk of exploration, development, and 
production efforts. Costs associated with drilling and platforms are the two most significant cost components in the offshore industry. ${ }^{17}$

We first calculate the conventional TFP using Equation (13). Our results indicate that from 1976 to 1995 , the average annual growth in output (i.e., oil and gas) was 1.30 percent, while the average growth in inputs (i.e., wells and platforms) was 1.75 percent. Thus, the conventional TFP, or net result of depletion and technological change, decreased on average 0.45 percent per year in the study period. The result suggests that, at the aggregate regional level and in the entire exploration-development-production process, the effect of technological change was unable to offset completely the effect of resource depletion from 1976 to $1995^{18}$.

Since the offshore oil and gas industry is a resource industry, it is necessary to make adjustments to the conventional TFP estimates (see Equation (13)) with respect to resource conditions (e.g., field size and water depth). We develop the adjustments as in Equation (13). We first estimate the adjusted TFP change by accounting for the depletion effects. Over the 1976-1995 study period and across all active fields in each year, average field size $(S)$ declined at an average rate of 14.62 percent per year, and average water depth $(D)$ rose, on average, 0.62 percent per year. As shown in Equation (6), the impacts of these two indexes on TFP estimate depend on the corresponding cost elasticities $\left(\varepsilon_{C S}\right.$ and $\left.\varepsilon_{C D}\right)$. However, we are unable to develop estimates of these elasticities in the study for lack of relevant data. Instead, we utilize sensitivity analysis to explore the range of the adjusted TFP. In the sensitivity analysis, we vary both $\varepsilon_{C S}$ and $\varepsilon_{C D}$ from 0.4 to 1.2 (see the discussion in Jin et al. 1998). The results of average annual TFP growth adjusted for field size and water depth are presented in Table 2.

17 For example, for a large field (280 million barrels oil equivalent), drilling cost and production operating cost account for over 75 percent of the total cost associated with the entire exploration, development and production process (Lewin and Associates, 1985). 
The adjusted average annual TFP growth ranges from $5.64 \%$ to $17.82 \%$, depending on the values of the cost elasticities. Generally, if the cost elasticities are larger, the corresponding TFP growth estimates will be higher. Although we cannot develop a point estimate, the results clearly show that true TFP growth in the offshore industry is significantly higher, when the effects of field size and water depth are accounted for (using Equation (13)), than conventional measurement.

During the study period, our environmental regulatory intensity index $(E)$ rose, on average, 6.27 percent per year and our pollution discharge index $(Q)$ declined at an average rate of 11.56 percent per year. Again, since we do not have necessary data to estimate relevant cost elasticities ( $\varepsilon_{C E}$ and $\varepsilon_{C Q}$ ), we employ sensitivity analysis to examine a wide range of possible values $(0.01-$ 0.1). Table 3 summaries the resulting estimates of average annual TFP growth, adjusted for water depth, field size, stringency of environmental regulations and pollution discharges (oil spills and produced waters). In the calculation, we set the cost elasticities for both water depth $\left(\varepsilon_{C D}\right)$ and field size $\left(\varepsilon_{C S}\right)$ at 0.8 (e.g., Fagan 1997, Jin et al. 1998).

As shown in Table 3, accounting for stringency of environmental regulations and pollution discharge leads to even greater adjusted TFP growth estimates. In our base case, the adjusted TFP growth is $11.73 \%$ (see Table 2 with $\varepsilon_{C D}=\varepsilon_{C S}=0.8$ ), the fully adjusted TFP growth ranges from $16.03 \%$ to $54.70 \%$ as the value of the cost elasticities ( $\varepsilon_{C E}$ and $\varepsilon_{C Q}$ ) vary from 0.01 to 0.1. The results further enhance our findings and clearly show that the true TFP growth, accounting for water depth, field size, environmental regulation, and pollution discharge, is well above the conventional measure. The pace of productivity improvement in the offshore oil and gas industry has been truly remarkable compared to standard productivity measurement.

18 See Managi et al. (2004b) for another filed level econometric analysis and the forecasting of oil and gas production. 


\section{Conclusions}

Offshore oil and gas operations in the Gulf of Mexico have played an important role in energy supply in the United States. In the past five decades, the offshore industry expanded first along the coast in shallow waters, and then extended into deep waters. Contrary to earlier predictions of declining production due to resource depletion (Walls 1994), the output from the region has increased in recent years (U.S. Department of Interior 2000). The continued development and production in the region has depended heavily on technological innovations.

In the study, we examine the role technological change has played in the offshore industry. We first analyze the effect of pollution discharge (e.g., produced water and oil spill), technological change on the production frontier using a unique field-level data set covering 1947 through 1998, and we then develop estimates of the growth in total factor productivity (TFP) in the industry at the regional level from 1976 to 1995.

Results of our stochastic frontier model suggest that the effect of technological change on the offshore oil and gas industry at the field level was substantial over the study period from 1947 to 1998 . Because of technological progress, the negative effect of resource depletion on field-level production frontier has been declining over time. Similarly, the negative impact of water depth on the production frontier has been falling. The results reveal that environmental regulation had a significantly negative impact on offshore production, although such impact has been diminishing over time due to technological change and improvement in management. Finally, the stochastic frontier analysis show that the production efficiency at the field level has been decreasing, which is likely due to the depletion of reserves and resulting expansion of exploration and production in deep waters. 
To measure the magnitude of technological progress, we develop estimates of the growth in TFP in the offshore industry in the Gulf of Mexico region. Our results indicate that the conventional TFP decreased on average 0.45 percent per year from 1976 to 1995, implying that at the aggregate regional level and in the entire exploration-development-production process, the effect of technological change was unable to offset completely the effect of resource depletion in this period. However, adjusted for field size and water depth, the average annual change in TFP grew at least 5.64 percent. Although we cannot provide a point estimate for lack of data, the results clearly show that true TFP growth in the offshore industry is significantly higher, when depletion effects associated with field size and water depth are accounted for. Also, the adjusted TFP growth estimates will be higher if the cost elasticities with respect to water depth or field size are larger.

In addition to water depth and field size, accounting for environmental regulatory stringency and pollution discharge leads to further increase in the estimates of adjusted TFP growth. For our sensitivity analysis, the low-end estimate of the fully adjusted TFP growth is 16.03 percent, and the actual growth may be much greater, depending on the values of the cost elasticities. In general, our results at both the field level and the regional level are consistent, and they clearly show that the pace of technological progress in the offshore oil and gas industry has been truly remarkable. 


\section{Appendix A: Nonrenewable Resource Model and Environmental Regulations}

Our empirical econometric equation of oil and gas production in this study is base on a dynamic profit-maximizing framework for nonrenewable resource industry (see Deacon, 1993; Krautkreamer, 1998; Kunce et al., 2004 for review in the literature). We use simplified version of exploration-extraction aggregated model (e.g., Livernois and Uhler, 1987). Hypothetical competitive firm makes optimal extraction and exploration decision with respect to reserves over one or many deposits in each aggregated field. The firm faces exogenous prices, is assumed to have complete property rights, and is assumed to maximize the present value of profits from exploration and extraction operations. Especially, following assumptions are utilized for our empirical specification. First, production cost function is assumed to have a log-log relationship to variables including factor inputs, technology, geological factors, and environmental regulations applied to production. Second, nonrenewable resource is extracted from a fixed stock of homogeneous quality. Solving present value Hamiltonian and after some tedious calculations, oil and gas production is shown to have a log-log relationship to variables in Equation (1).

Several studies have examined how the oil and gas industry responds to changes in environmental regulations (e.g., Stollery, 1985; Jin and Grigalunas, 1993a; Dension et al., 1995; Kunce et al., 2004). Ideally, the model needs to consider the effects of the regulations to all stages of oil and gas operations: exploration, development, and production (see Jin and Grigalunas, 1993a). Empirically, however, it is difficult to obtain the data of the regulations. For example, recent study by Kunce et al. (2004) studies the environmental regulations pertaining to drilling. The drilling fluids, drill cuttings, deck drainage, well treatment fluids, proposal sand, and sanitary and domestic wastes are also important factors in the regulations in addition to the environmental regulations applied to production. We only consider the compliance cost of the 
regulations applied to production since these data is not available in field level. This may not be a terrible assumption since there is more regulation on production side than drilling (See EPA (1976, 1985, 1993, 1999) and Managi (2002) for detailed history of the regulations).

\section{Appendix B. Missing Data Estimation}

Complete data for porosity is available for only 390 fields out of 933 fields, with more data available in more recent years. We use two-step estimation procedure to correct for censoring of observations (Heckman 1979; Greene 1981). Table A1 and A2 contains estimation results from these regression models. In the first stage results, Probit is applied to determine the likelihood that a porosity measure is missing, and discovery year is the explanatory variable. Porosity is the dependent variable in the second stage, and the explanatory variables are oil reserves in the field, gas reserves in the field, water depth and the number of exploratory wells drilled in the first five years following discovery of the field. Results for second stage indicate that higher porosity values tend to be found in larger reservoirs, in reservoirs in which more drilling occurs and in deeper-water fields (Table A2).

Table A1. Stage I Probit Estimates

\begin{tabular}{lll}
\hline Independent Variable & Estimated Coefficient & Standard Error \\
\hline Intercept & $811.234 * * *$ & 65.866 \\
Discovery Year & $-106.926 * * *$ & 8.679 \\
\hline & & \\
\hline
\end{tabular}

Note: Dependent variable $=1$ if porosity observed; 0 otherwise. $* * *$ Significant at the 1 percent level. 


\section{Table A2. Stage II Estimates}

\begin{tabular}{|c|c|c|}
\hline Dependent Variable & Porosity & \\
\hline Independent Variable & Estimated Coefficient & Standard Error \\
\hline Intercept & $-134.649 *$ & 68.843 \\
\hline $\ln ($ oil reserve $)$ & $0.554 *$ & 0.335 \\
\hline $\ln ($ gas reserve $)$ & $2.409 * * *$ & 0.41542 \\
\hline $\ln ($ water depth) & $15.145 *$ & 7.91355 \\
\hline $\ln (5 Y r$ exp drill $)$ & $1.05296 * * *$ & 0.22748 \\
\hline IMR & $5.11798 * *$ & 1.753 \\
\hline $\mathrm{R}^{2}$ & 0.206 & \\
\hline Adj. $R^{2}$ & 0.196 & \\
\hline
\end{tabular}

Note: The variable 5Yr exp drill is cumulative drilling feet of exploration wells in the field for first 5 years following discovery. 50 percent of total drilling is completed on average 5.2 year, therefore we choose 5 year, based on the assumption that MMS has data for large fields. IMR stands for Inverse Mills Ratio.

*** Significant at $1 \%$ level; $\quad * *$ Significant at 5\% level; $\quad *$ Significant at $10 \%$ level. 


\section{References}

Aigner, D.J., C.A.K. Lovell. and P. Schmidt. 1977. Formulation and Estimation of Stochastic Frontier Production Function Models Journal of Econometrics 6: 21-37.

American Petroleum Institute. Independent Petroleum Association of America, and Mid-Continent Oil \& Gas Association. various years. Joint Association Survey on Drilling Costs. API, Washington, D.C.

American Petroleum Institute. 1995. Potential Impact of Environmental Regulations on the Oil and Gas Exploration and Production Industry. March. API, Washington, DC.

Barbera, A.J. and V.D. McConnell. 1990. The Impact of Environmental Regulations on Industry Productivity: Direct and Indirect Effects. Journal of Environmental Economics and Management 18(1): 50-65.

Battese, G.E. and T.J. Coelli. 1992. Frontier Production Functions, Technical Efficiency and Panel Data: With Application to Paddy Farmers in India Journal of Productivity Analysis 3: 153-169.

Baumol, W.J., and W.E.Oates. 1988. The Theory of Environmental Policy 2nd edition, Cambridge: Cambridge University Press.

Bohi, D.R. 1997. Changing Productivity of Petroleum Exploration and Development in the U.S. Draft Report. January. Resources For The Future. Washington, D.C.

Christensen, L.R. and D.W. Jorgenson, 1995. Measuring Economic Performance in the Private Sector In D.W. Jorgenson Productivity Volume 1: Postwar U.S. Economic Growth. MIT Press.

Cleveland, C.J. and R. Kaufmann. 1997. Natural Gas in the U.S.: How Far Can Technology Stretch the Resource Base? The Energy Journal 18 (2): 89-108.

Coelli,T.J.. 1994. A Guide to FRONTIER Version 4.1: A Computer Program for Stochastic Frontier and Cost Function Estimation, Department of Econometrics, University of New England, Armidale.

Cropper, Maureen L. and Wallace E. Oates. 1992. Environmental Economics: A Survey. Journal of Economic Literature 30 (2): 675-740.

Cuddington, J.T., and D. L. Moss. 2001. Technical Change, Depletion and the U.S. Petroleum Industry: A New Approach to Measurement and Estimation. American Economic Review 91(4): 1135-1148.

Deacon, R. 1993. Taxation, Depletion, and Welfare: A Simulation Study of the U.S. Petroleum Resource. Journal of Environmental Economics and Management 24 (2): 159-187.

Denison, D., T. Crocker, and G. Briand. 1995. The Impact of Environmental Controls on Petroleum Exploration, Development, and Extraction. In The New Global Oil Market: Understanding Energy Issues in the World Economy. S. Shojai ed. Praeger Publishers, Wesport, Connecticut and London. 
Denny, M., M. Fuss and L. Waverman. 1981. The Measurement and Interpretation of Total Factor Productivity in Regulated Industries, with an Application to Canadian Telecommunications. In Productivity Measurement in Regulated Industries. T.G. Cowing and R.E. Stevenson ed. Academic Press, New York.

Diewert, W.E. 1976. Exact and Superlative Index Numbers. Journal of Econometrics 4:115-145.

Diewert, W.E. 1978. Superlative Index Numbers and Consistency in Aggregation. Econometrica 46(4):883-900.

Diewert, W.E. 1992. The Measurement of Productivity. Bulletin of Economic Research 44(3): 163-198.

Engineering News Record [ENR]. 2000. ENR Market Trends, ENR Index Review, Construction Cost Index. Engineering News Record.

Fagan, M.N. 1997. Resource Depletion and Technical Change: Effects on U.S. Crude Oil Finding Costs from 1977 to 1994. The Energy Journal 18(4): 91-105.

Farrow, R.S., J.M. Broadus, T.A. Grigalunas, P. Hoagland and J.J. Opaluch, 1990. Managing the Outer Continental Shelf Lands: Ocean of Controversy. Taylor and Francis, New York.

Färe, R., S. Grosskopf, and C.A. Knox. Lovell. 1985. The Measurement of Efficiency of Production. Boston: Kluwer-Nijhoff.

Fisher, I. 1922. The Making of Index Numbers. Houghton Mifflin Company, Boston.

Fuss, Melvin and Daniel McFadden, 1978. Production Economics: A Dual Approach to Theory \& Applications Amsterdam: North-Holland.

Giuliano, F.A. 1981. Introduction to Oil and Gas Technology. Second Edition. International Human Resources Development Corporation, Boston, MA.

Gollop, F.M. and M.J. Roberts. 1983. Environmental Regulations and Productivity Growth: The Case of Fossil-fueled Electric Power Generation. Journal of Political Economy 91(4): 654-674.

Greene, William. 1981, Sample Selection Bias as a Specification Error: Comment, Econometrica 49(3) 795-98.

Harrington, Winston, Richard D. Morgenstern, Peter Nelson. 2000, On the Accuracy of Regulatory Cost Estimates. Journal of Policy Analysis and Management 19 (2): 297-322.

Heckman, James. 1979. Sample Selection Bias as a Specification Error. Econometrica 47(1): 153-161.

Hjalmarsson, Lennart, Subal C. Kumbhakar, Almas Heshmati. 1996. DEA, DFA and SFA: A Comparison. Journal of Productivity Analysis 7 (2-3): 303-27.

Hulten, C.R. 1986. Productivity Change, Capital Utilization, and the Sources of Efficiency Growth. Journal of Econometrics 33:31-50.

Jin, D. and T.A. Grigalunas. 1993a. Environmental Compliance and Energy Exploration and Production: Application to Offshore Oil and Gas. Land Economics 69(1):82-97. 
Jin, Di, and T.A. Grigalunas. 1993b. Environmental Compliance and Optimal Oil and Gas Exploitation. Natural Resource Modeling 7(4): 331-352.

Jin. Di, H. Kite-Powell, and M. Schumacher. 1998. Total Factor Productivity Change in the Offshore Oil and Gas Industry. Woods Hole Oceanographic Institution Working Paper.

Jorgenson, D.W. and Z. Griliches. 1967. The Explanation of Productivity Change. Review of Economic Studies 34(3): 249-280.

Krautkreamer, J.A. 1998. Nonrenewable Resource Scarcity. Journal of Economic Literature 36: 2065-107.

Livernois, J. and R.S. Uhler. 1987. Extraction Costs and the Economics of Nonrenewable Resources. Journal of Political Economy 95: 195-203.

Kunce M., S. Gerking, and W. Morgan. 2004. Environmental and Land Use Regulation in Nonrenewable Resource Industries: Implications from the Wyoming Checkerboard, Land Economics 80 (1): 7694.

Lewin and Associates, Inc. 1985. Replacement Costs of Domestic Crude Oil. vol.1-2. DOE/FE30014-1. Prepared for U.S. Dept. of Energy, Washington, D.C.

Livernois, J.R. and R.S. Uhler. 1987. Extraction Costs and the Economics of Nonrenewable Resources. Journal of Political Economy 95(1): 195-203.

Löthgren, Mickael. 1997. Generalized Stochastic Frontier Production Models, Economics Letters 57 (3): 255-59.

Managi, Shunsuke. 2002 Technological Change, Depletion and Environmental Policy in Offshore Oil and Gas Industry. Ph.D. diss., University of Rhode Island.

Managi, S. J.J. Opaluch, D. Jin, and T.A. Grigalunas. 2004a. Technological Change and Depletion in Offshore Oil and Gas, Journal of Environmental Economics and Management 47 (2): 388-409.

Managi, S., J.J. Opaluch, D. Jin, and T.A. Grigalunas. 2004b. Forecasting Energy Supply and Pollution from the Offshore Oil and Gas Industry. Marine Resource Economics 19 (3): 307-332.

Managi, S. J.J. Opaluch, D. Jin, and T.A. Grigalunas. 2005a. Technological Change and Petroleum Exploration in the Gulf of Mexico, Energy Policy 33 (5): 619-632.

Managi, S., J.J. Opaluch, D. Jin, and T.A. Grigalunas. 2005b. Environmental Regulations and Technological Change in the Offshore Oil and Gas Industry. Land Economics 81 (2) 303-319.

Managi, S., J.J. Opaluch, D. Jin, and T.A. Grigalunas. 2006. Alternative Innovation Indexes in the Offshore Oil and Gas Industry. Applied Economics Letters (forthcoming,).

Massachusetts Institute of Technology. 1973. The Georges Bank Petroleum Study: Summary. vol.1-2. Offshore Oil Task Group, Cambridge, MA.

Meeusen, W. and van den Broeck, J. 1977. Efficiency Estimation from Cobb- Douglas Production Functions With Composed Error. International Economic Review 18: 435-444. 
Moss D. L. 1993. Measuring Technical Change in the Petroleum Industry: A New Approach to Assessing its Effect on Exploration and Development. National Economic Research Associations, Working Paper Number 20.

Pindyck, R.S. 1978. The Optimal Exploration and Production of Nonrenewable Resources. Journal of Political Economy 86(5): 841-861.

Ray, Subhash C. and Evangelia Desli. 1997. Productivity Growth, Technical Progress, and Efficiency Change in Industrialized Countries: Comment. American Economic Review 87 (5): 1033-39.

Solow, R.M. 1957. Technical Progress and the Aggregate Production Function. Review of Economics and Statistics 39:312-320.

Stijn, R., Lovell, C.A.K., Thijssen, G. 2002. Analysis of Environmental Efficiency Variation. American Journal of Agricultural Economics 84 (4): 1054-1065.

Stollery, K. 1985. Environmental Controls in Extractive Industries. Land Economics 61: 136-44.

U.S. Department of Energy. various years. Cost and Indices for Domestic Oil and Gas Field Equipment and Production Operations. Energy Information Administration, Washington, DC.

U.S. Department of Energy. 1982. Outer Continental Shelf (OCS) Oil and Gas Supply Model. vol.1-3, DOE/EIA-0372/1-3. Energy Information Administration, Washington, DC.

U.S. Department of Energy. 1993. Drilling Sideways: A Review of Horizontal Well Technology and Its Domestic Application. DOE/EIA/TR-0565. Energy Information Administration, Washington, D.C.

U.S. Department of the Interior. 1996. Offshore Statistics Second Quarter. Minerals Management Services, Operations and Safety Management, Herndon, VA.

U.S. Department of the Interior. 1997. Federal Offshore Statistics: 1995. OCS Report MMS 97-0007. Minerals Management Services, Operations and Safety Management, Herndon, VA.

U.S. Department of Interior, 2001. Technical Information Management System (TIMS) Database, U.S. Mineral Management Service (MMS).

U.S. Environmental Protection Agency. 1976. Development Document for Interim Final Effluent Limitations Guidelines and New Source Performance Standards for the Oil and Gas Extraction Point Source Category. Washington D.C.: Environmental Protection Agency.

U.S. Environmental Protection Agency. 1985. Economic Impact Analysis of Proposed Effluent Limitations and Standards for the Offshore Oil and Gas Industry. Washington D.C.: Environmental Protection Agency.

U.S. Environmental Protection Agency. 1993. Economic Impact Analysis of Final Effluent Limitations Guidelines and Standards for the Offshore Oil and Gas Industry. Washington D.C.: Environmental Protection Agency. 
U.S. Environmental Protection Agency. 1999. Environmental Assessment of Proposed Effluent Limitations Guidelines and standards for Synthetic-Based Drilling Fluids and other NonAqueous Fluids in the Oil and Gas Extraction Point Source Category. Washington D.C.: Environmental Protection Agency.

Walls, M.A. 1994. Using a 'Hybrid' Approach to Model Oil and Gas Supply: A Case Study of the Gulf of Mexico Outer Continental Shelf. Land Economics 70(1): 1-19. 
Table 1. Parameter Estimates of Stochastic Frontier Model

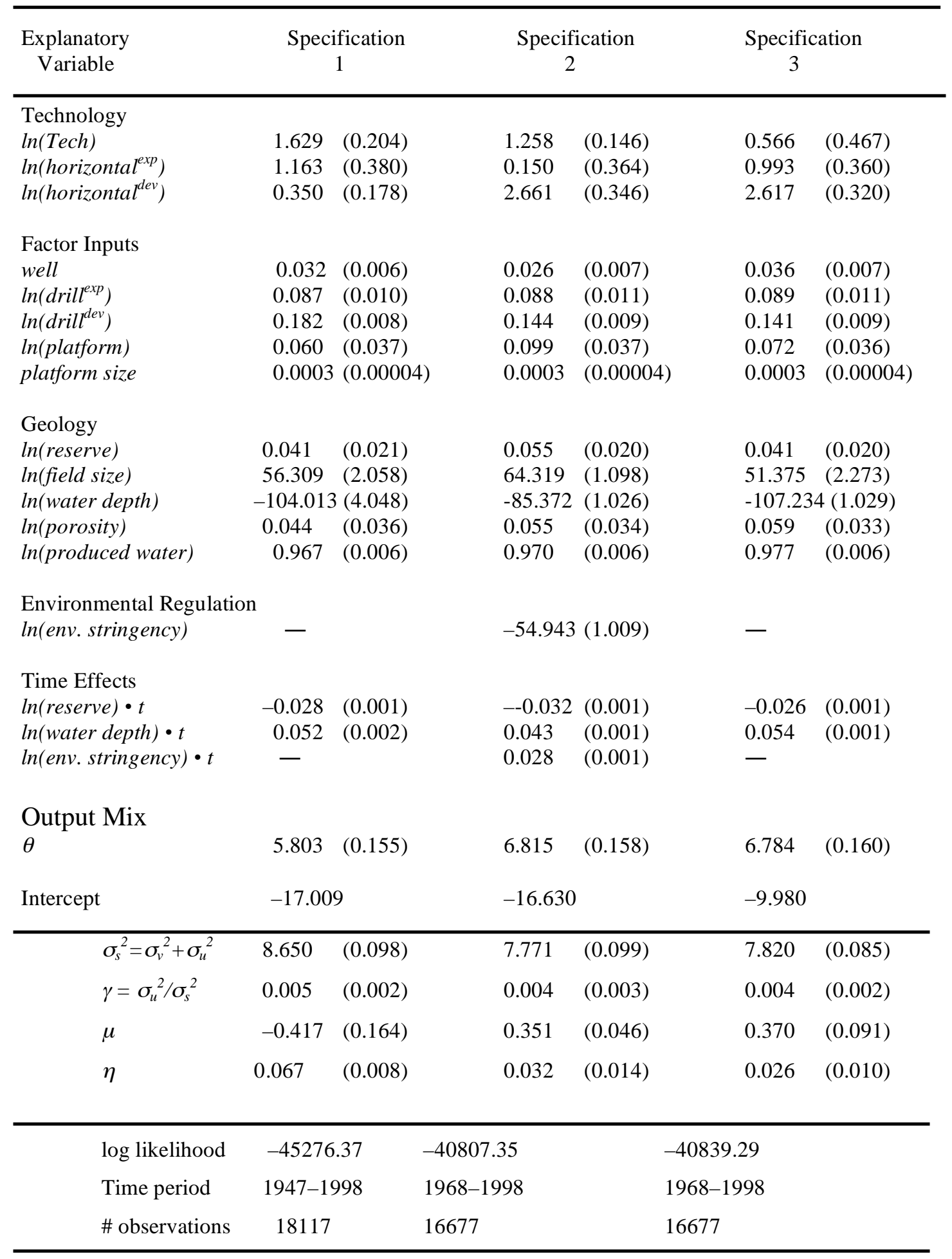

Note: Dependent variable is the natural $\log$ of the norm $(\iota)$. Standard errors are reported in parentheses. 
Table 2. Average Annual TFP Growth (Percent) in the Gulf of Mexico Offshore Oil and Gas Industry (1976-1995), Adjusted for Water Depth and Field Size

\begin{tabular}{|l|ccccc|}
\hline$\varepsilon_{C D}$ & & & & & \\
0.4 & 5.64 & 8.56 & 11.48 & 14.41 & 17.33 \\
0.6 & 5.76 & 8.68 & 11.61 & 14.53 & 17.45 \\
0.8 & 5.88 & 8.81 & 11.73 & 14.65 & 17.58 \\
1.0 & 6.01 & 8.93 & 11.85 & 14.78 & 17.70 \\
1.2 & 6.13 & 9.05 & 11.98 & 14.90 & 17.82 \\
\hline \multicolumn{7}{r}{} & $\varepsilon_{C S}$ & 0.4 & 0.6 & 0.8 & 1.0 & 1.2
\end{tabular}

Notes: $\varepsilon_{C S}$ is the cost elasticity with respect to field size, and $\varepsilon_{C D}$ is the cost elasticity with respect to water depth. 
Table 3. Average Annual TFP Percentage Growth in the Gulf of Mexico Offshore Oil and Gas Industry (1976-1995), Adjusted for Water Depth, Field Size, Environmental Regulation, and Pollution Discharge

\begin{tabular}{|lllllllllll|}
\hline$\varepsilon_{\mathrm{CE}}$ & 0.01 & 0.02 & 0.03 & 0.04 & 0.05 & 0.06 & 0.07 & 0.08 & 0.09 & 0.10 \\
\hline$\varepsilon_{C Q}$ & & & & & & & & & & \\
& & & & & & & & & & \\
0.01 & 16.03 & 16.09 & 16.16 & 16.23 & 16.30 & 16.37 & 16.44 & 16.50 & 16.57 & 16.64 \\
0.02 & 20.25 & 20.32 & 20.39 & 20.46 & 20.53 & 20.60 & 20.66 & 20.73 & 20.80 & 20.87 \\
0.03 & 24.48 & 24.55 & 24.62 & 24.69 & 24.76 & 24.82 & 24.89 & 24.96 & 25.03 & 25.10 \\
0.04 & 28.71 & 28.78 & 28.85 & 28.92 & 28.98 & 29.05 & 29.12 & 29.19 & 29.26 & 29.32 \\
0.05 & 32.94 & 33.01 & 33.08 & 33.14 & 33.21 & 33.28 & 33.35 & 33.42 & 33.49 & 33.55 \\
0.06 & 37.17 & 37.24 & 37.30 & 37.37 & 37.44 & 37.51 & 37.58 & 37.65 & 37.71 & 37.78 \\
0.07 & 41.40 & 41.47 & 41.53 & 41.60 & 41.67 & 41.74 & 41.81 & 41.87 & 41.94 & 42.01 \\
0.08 & 45.63 & 45.69 & 45.76 & 45.83 & 45.90 & 45.97 & 46.03 & 46.10 & 46.17 & 46.24 \\
0.09 & 49.85 & 49.92 & 49.99 & 50.06 & 50.13 & 50.19 & 50.26 & 50.33 & 50.40 & 50.47 \\
0.10 & 54.08 & 54.15 & 54.22 & 54.29 & 54.35 & 54.42 & 54.49 & 54.56 & 54.63 & 54.70 \\
\hline
\end{tabular}

Notes: $\varepsilon_{\mathrm{CE}}$ is the cost elasticity with respect to environmental regulatory intensity, and $\varepsilon_{\mathrm{CQ}}$ is the cost elasticity with respect to pollution discharge. 


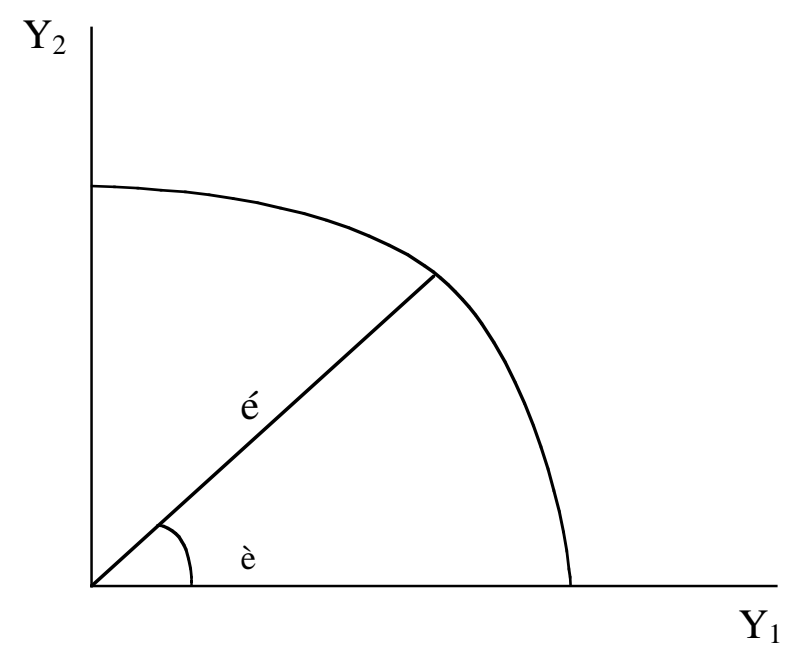

Figure 1. Polar Representation of Multiple Outputs 